Current Research in Psychology 2 (1): 108-114, 2011

ISSN 1949-0178

(C) 2011 Science Publications

\title{
Considering Competition Avoidant Individuals Via the Big Five Model
}

\author{
${ }^{1}$ Richard M. Ryckman, ${ }^{2}$ Bill Thornton, ${ }^{1}$ Joel A. Gold and ${ }^{1}$ Shawn Collier \\ ${ }^{1}$ Department of Psychology, University of Maine, \\ Orono, Maine 04469-5742, USA \\ ${ }^{2}$ Department of Psychology, University of Southern Maine, \\ Portland, Maine 04104-9300, USA
}

\begin{abstract}
Problem statement: This study sought to increase our understanding of the personality characteristics of competition avoidant individuals by examining differential associations between the Big Five personality traits and competition avoidance. Approach: Participants $(n=169)$ completed a questionnaire set including relevant assessments, the Competition Avoidance Scale and the Five-Factor Model Inventory with subscales for Neuroticism, Extraversion, Openness to Experience, Conscientiousness and Agreeableness. Correlation and regression analyses examined the relationship between competitive orientation. Results: As predicted, results indicated that Neuroticism, Extraversion and Openness to Experience were all associated negatively with competition avoidance; thus, individuals higher on competition avoidance were more emotionally unstable, introverted and less open to experience than those who scored lower on the dimension. Agreeableness and Conscientiousness were unrelated to competition avoidance. Conclusion: Discussion considered the potential use of the competition avoidance scale by counselors and coaches as a diagnostic assessment to identify such individuals early in their academic and sports undertakings and enable support in these competitive environments.
\end{abstract}

Key words: Competitive attitude, competitive orientation, big five, Five-Factor Model (FFM), Eysenck Personality Questionnaire (EPQ), mental health and counseling

\section{INTRODUCTION}

In her theory of neurosis, Horney (1973) argued that individuals who recoil from competition are, at base, neurotically competitive, but they check their ruthless ambition because of excessive fear of losing the approval and affection of others. Specifically, she thought that these competition avoiders fear being successful in competition because they believe others will resent and dislike them for their victories. They also fear failure in competition because they believe that others will then think less of them, inferring that they are incapable or ineffectual and therefore dislike them. Under either circumstance, such individuals will try to avoid competing whenever they can. If they must compete, they are so afraid of succeeding that they may engage in self-handicapping strategies to lessen the chance of success; and, should they near victory, they may minimize their efforts thereby making it unlikely that they would succeed. Also, they are likely to belittle themselves or otherwise engage in selfderogation to minimize further any interpersonal implications associated with a competitive outcome, whether success or failure.

In this study, we sought to further our understanding of the personality of competition avoiders by examining such individuals within the context of the Five-Factor Model (FFM; Costa and Widiger, 2002; Goldberg, 1990; Costa and McCrae, 1992; McCrae and Costa, 1987; Wiggins, 1996). One of the more popular super-trait paradigms in personality psychology today, the FFM specifies five broadband traits, otherwise known as the "Big Five," that include Neuroticism, Extraversion,Openness to Experience, Conscientiousness and Agreeableness.

Horney (1973) defined competition avoidance as a form of neurotic competitiveness. Indeed, recent research by Ryckman et al. (2009) did verify that individuals higher in competition avoidance were more neurotic (i.e., emotionally unstable, temperamental, self-conscious and vulnerable) than those lower in competition avoidance using the Neuroticism Scale of the Eysenck Personality Questionnaire (EPQ; Eysenck and Eysenck, 1994). Although neuroticism in the FFM is defined similarly to

(C) 2011 Richard M. Ryckman, Bill Thornton, Joel A. Gold and Shawn Collier. This open access article is distributed under a Creative Commons Attribution (CC-BY) 3.0 license which permits unrestricted use, distribution, and reproduction in any medium, provided the original work is properly credited. DOI: 10.3844/crpsp.2011.108.114 
that of the EPQ, it is important to note that the Big Five scale is scored such that higher scores reflect less neuroticism, whereas higher scores on the equivalent scale in the EPQ indicate greater neuroticism. Regardless, in using the neuroticism scale of the FFM, the present study would provide for a reevaluation of Horney's major contention regarding competition avoidance being a neurotic predisposition.

Hypothesis 1: There will be a negative association between competition avoidance and the FFM's neuroticism scale; as such, the greater the competition avoidance of the individual, the less the individual's emotional stability (i.e., more neurotic).

Horney (1973) also conjectured that recoiling from competition was based on a strong fear of negative evaluations from others and Ryckman et al. (2009) reported data supporting this claim. Thus, their fear of being negatively evaluated by others may lead competition avoiders to stay away from others, to "stay in the corner", to be modest, passive and, above all, to be inconspicuous. With the extraversion factor of the Big Five in mind, this leads to the following prediction:

Hypothesis 2: There will be a negative correlation between competition avoidance and extraversion; as such, the greater the competition avoidance of the person, the less extraverted and outgoing the person will be.

Finally, Horney (1973) thought competition avoiders had a strong fear of success and failure, a finding also substantiated by Ryckman et al. (2009). As a result, they would adhere to conventional standards and maintain normative behavior, prefer the routine rather than variety and be very anxious about formulating their own goals and attempting original, creative solutions to problems. Thus, the following prediction considering the Big Five's openness to experience factor.

Hypothesis 3: There will be a negative association between competition avoidance and openness to experience; the greater the competition avoidance, the less open to experience.

In regard to the remaining two super-traits of the Big Five, Conscientiousness and Agreeableness, it is difficult to make clear-cut predictions based on Horney's theorizing. As for conscientiousness, Horney (1973) thought that competition avoiders would work conscientiously, perhaps even frantically, in preparation of an examination or other assessment in order to circumvent failure and thereby avoid the criticism and derogation from others who learn of their poor performance. On the other hand, competition avoiders may behave in an opposite manner, make little or no effort and therefore achieve little success, so as to not to incur the resentment of others or risk losing the approval and affection of others due to their ambitions. Based on these inconsistent or contradictory needs and motives of those who recoil from competition, we expected no correlation between competition avoidance and conscientiousness.

Finally, we would expect a positive association between competition avoidance and the Big Five's agreeableness factor, if we focus on the fact that Horney thought that competition avoiders were more modest and conforming to the will and opinions of others, a conjecture supported by the research of Ryckman et al. (2009) Under these circumstances, we would expect that competition avoiders would be pleasant, agreeable and acquiescent in their social interactions. On the other hand, it is likely that competition avoiders would not act in a straightforward or trustworthy manner with others, (Ross et al., 2003) key facets of agreeableness. Indeed, Horney (1973) pointed out that competition avoiders may characteristically feel a keen sense of inferiority and harbor antisocial feelings that they try to conceal from others. Thus, outwardly they may appear to be modest and accepting of (perhaps conforming to) the opinions of others, but inwardly they are suspicious of others, fear them and may be ruthless and hostile toward others. Thus, with such conflicting needs and motives, we would expect no relationship between competition avoidance and the agreeableness factor.

\section{MATERIALS AND METHODS}

Participants and Procedure: Participants were 169 undergraduates (78 males and 91 females) at a public university in the northeastern United States who volunteered to participate in the study to earn extra credit in their introductory psychology class. The mean age of the males was 20.53 years $(\mathrm{SD}=4.59)$ and ranged from 18 to 49 years; for the females, the mean age was 19.84 years $(\mathrm{SD}=4.34)$ and ranged from 18 to 48 years. The difference in age between males and females was not significant $(\mathrm{t}=1.00)$.

In a large group session, study participants were informed that they would be completing a set of personality questionnaires ostensibly for establishing baseline responses for later research. To minimize the potential influence of response biases, they first completed and submitted an informed consent form. They then continued on to respond anonymously to the assessments described below. At the end of the session, participants were thanked for their participation and provided a debriefing sheet with descriptions of the 
personality inventories they completed and an explanation of the hypotheses being tested.

\section{Instruments:}

Competition avoidance scale: The Competition Avoidance Scale is a 22-item measure that provides for a valid and reliable assessment of individuals' tendency to avoid competition (Ryckman et al., 2009). Participants respond to individual items using a 5-point Likert-scale ranging from 1 (strongly disagree) to 5 (strongly agree). Total scores can range from 22-110, with higher scores indicating a greater predisposition to avoid competition. Sample items include: "“I avoid competing because others will not like me if I lose" and "There's nothing so great about winning in competition, especially when it causes others to dislike you." Internal consistency, based on Cronbach's alpha coefficient, was 0.83 in the present study.

International personality item pool five-factor model inventory: The 50-item IPIP FFM measure (Mervielde, 1999) was used to assess the broad Big Five traits of Neuroticism, Extraversion, Openness to Experience, Conscientiousness andAgreeableness. This inventory is used increasingly by researchers because it has a short administration time, is a valid and reliable assessment andshows an equivalent factor structure across gender and a variety of ethnic groups (Ehrhart et al., 2008). Each of the following five factors has 10-items. For each item, respondents use a 5-point Likert-scale to describe themselves, ranging from 1 (very inaccurate) to 5 (very accurate). Total scores on each scale can range from 10-50.

Neuroticism: This scale measures the emotional stability of the individual. Emotionally stable people are even-tempered, confident, poised and self-reliant. Higher scores indicate greater emotional stability (lower neuroticism), whereas lower scores indicate less emotional stability (higher neuroticism). Sample items include: "I am relaxed most of the time" and "I seldom feel blue." Internal consistency was 0.88 .

Extraversion: This scale measures the extraversion of the person. Extraverted people are sociable, gregarious and assertive. Higher scores indicate greater extraversion. Sample items include: "I am the life of the party" and "I don't mind being the center of attention." Internal consistency is 0.87 .

Openness to experience: This scale assesses the person's openness to experience. People who are open to experience are imaginative, unconventional, curious and original. Higher scores indicate greater openness to experience. Sample items include: "I have a vivid imagination" and "I have a rich vocabulary." Internal consistency was 0.81 .

Conscientiousness: This scale measures the conscientiousness of the individual. Conscientious people are hard-working, well-organized, careful, dependable and responsible. Higher scores indicate a higher level of conscientiousness. Sample items include: "I pay attention to details" and "I am exacting in my work." Internal consistency was 0.85 .

Agreeableness: This scale assesses the agreeableness of the individual. Agreeable people are warm, generous, good-natured, trusting and altruistic. Higher scores indicate greater agreeableness. Sample items include: "I sympathize with others' feelings" and "I take time out for others." Internal consistency was 0.81 .

\section{RESULTS}

Zero-Order correlational analyses: Table 1 presents the inter-correlations among all the variables. As predicted, competition avoidance was associated negatively with Neuroticism $(\mathrm{r}=-0.32, \mathrm{p}<0.001)$, Extraversion $(\mathrm{r}=-0.35, \mathrm{p}<0.001)$ and Openness to Experience $(\mathrm{r}=-0.17, \mathrm{p}<0.05)$. These relationships indicate that individuals higher in competition avoidance report being more emotionally unstable, introverted and less open to experience than people who score lower on the competition avoidance dimension. Competition avoidance was not correlated significantly with either Conscientiousness or Agreeableness ( $\mathrm{rs}=-$ 0.09 and 0.03 , respectively).

Considering relationships among the Big Five, Neuroticism (with high scores indicative of more emotional stability) was associated with greater Extraversion $(\mathrm{r}=0.20, \mathrm{p}<0.01)$ and less Agreeableness $(\mathrm{r}$ $=-0.18, p<0.05$ ), but was unrelated to either Openness to Experience or Conscientiousness (rs < 0.01). Consistent with their out-going nature, those scoring high on Extraversion also indicated greater Openness to Experience $(\mathrm{r}=0.18, \mathrm{p}<0.05)$ and Agreeableness $(\mathrm{r}=$ $0.26, \mathrm{p}<0.001$ ). And Agreeableness and Conscientiousness were positively related $(r=0.18, p<0.05)$.

\begin{tabular}{|c|c|c|c|c|c|c|c|}
\hline Variable & 2 & 3 & 4 & 5 & 6 & 7 & 8 \\
\hline Competition avoidance & -0.32 & $-0.35^{* * *}$ & $*_{-} 0.17 *$ & -0.09 & 0.03 & 0.06 & 0.04 \\
\hline Neuroticism & -- & $0.20 * *$ & -0.01 & -0.00 & $0.18 *$ & $-0.26 * * *$ & 0.07 \\
\hline Extraversion & & -- & $0.18^{*}$ & 0.07 & $0.26^{* * *}$ & 0.09 & 0.02 \\
\hline Openness to experience & & & -- & 0.08 & 0.00 & -0.11 & 0.06 \\
\hline Conscientiousness & & & & -- & $0.18^{*}$ & 0.14 & 0.09 \\
\hline Agreeableness & & & & & -- & $0.45^{* * * *}$ & 0.07 \\
\hline Sex & & & & & & -- & -0.08 \\
\hline Age & & & & & & & -- \\
\hline
\end{tabular}


Current Research in Psychology 2 (1): 108-114, 2011

Table 2: Hierarchical regression analysis for competition avoidance

\begin{tabular}{lllll}
\hline Variable & $\beta$ & $\mathrm{t}$ & $\mathrm{R}^{2}$ & $\Delta \mathrm{R}^{2}$ \\
\hline Step 1 & & & & \\
Sex & 0.057 & 0.741 & 0.003 & \\
Step 2 & & & $0.207^{* *}$ & $0.204^{* *}$ \\
Neuroticism & -0.247 & $-3.27^{* *}$ & & \\
Extraversion & -0.290 & $-3.78^{* *}$ & & \\
Openness to experience & -0.121 & $-1.68^{*}$ & & \\
Conscientiousness & -0.075 & -1.04 & & \\
Agreeableness & 0.091 & 1.10 & & \\
\hline Note: One-tailed tests; ${ }^{*}: \mathrm{p}<0.05^{* *}: \mathrm{p}<0.001$ & &
\end{tabular}

Finally, participant gender (coded males $=1$, females = 2) was associated negatively with Neuroticism $(r=-0.26, p<0.001)$ and positively with Agreeableness $(\mathrm{r}=0.45, \mathrm{p}<0.001)$. Thus, males were more emotionally unstable than females, whereas females expressed greater agreeableness than males. Age of was unrelated to competition avoidance and all of the Big Five traits (all rs $<0.10$ ).

Hierarchical regression analysis: In further consideration of the association between competition avoidance and each of the Big Five traits, a hierarchical regression analysis was conducted with competition avoidance as the criterion with gender entered in Step 1, then followed by the Big Five traits as a block in Step 2 . The results are shown in Table 2. After consideration of gender, the contribution of the Big Five scales to the prediction of competition avoidance accounted for approximately $20 \%$ of the variance in competition avoidance. In particular, competition avoidance was negatively predicted by Neuroticism $(\mathrm{t}=-3.27, \mathrm{p}<$ $0.001)$, Extraversion $(\mathrm{t}=-3.78, \mathrm{p}<0.001)$ and Openness to Experience $(\mathrm{t}=-1.68, \mathrm{p}<0.05)$. Inclusion of Conscientiousness and Agreeableness did not contribute significantly to the regression (ts $\leq 1.10$ ).

\section{DISCUSSION}

The results of the present investigation, supportive of the three primary hypotheses, increase our understanding of the personalities of competition avoiders in several important ways. First, as Horney theorized, those who avoid competitive encounters tend to be neurotic, otherwise emotionally unstable, temperamental and are anxious and fearful in the presence of others. This finding essentially replicates that of Ryckman et al. (2009) Second, in further corroboration of Horney's theorizing, those who recoil from competition fear negative reactions from others and perhaps leads them to be introverted, characteristically quiet, reserved and unsociable. They remain inwardly focused on themselves and keep socializing with others to a minimum. And third, perhaps in keeping with their introverted nature, they are less open to experience, preferring the routine and conventional path rather than risk being different with original, creative, or otherwise imaginative undertakings.

Due to the different needs and motives of those who avoid competition, the relationship between competition avoidance and Conscientiousness and with Agreeableness, could have been either positive or negative for both. However, the absence of any relationships in the present study was as expected given the otherwise conflicting needs and motives competition avoiders are presumably dealing with in general. Perhaps directional relationships involving these two dimensions of the Big Five would emerge, but only in consideration of the specific situation rather than as a general orientation. For example, Conscientiousness may positively correlate with competition avoidance when the "fear of failure" in a competitive situation is paramount. In contrast, a negative correlation may be obtained when the individual's "fear of success" is dominant. Then, it may also be a matter as to what the competition avoider would be conscientious about-well-organized, concerted efforts intended to achieve success or welldesigned self-handicapping strategies intended to mitigate failure. On the other hand, as Eysenck (1991) maintains, it may be that neither Conscientiousness nor Agreeableness are super-traits as Big-Five proponents maintain and, instead, are simply primary traits inappropriately included.

The recoiling from competition, as characterized by Horney (1973) is a rather unique neurotic striving and substantiated by the results of the present study and previous research (Ryckman et al., 2009). With the competition avoidance scale, it is possible to assess this disposition among students in college and high school and perhaps middle-school. Indeed, other ressearch has reported many students in middle school, high school and college to be avoidance oriented with regard to achievement and experience greater anxiety regarding academic competition, have lower self-esteem and selfefficacy and, consequently, poorer academic performance (Elliot and Sheldon, 1997; Urdan and Mestas, 2006; Skaalvik, 1997). As such, assessment of this trait would enable counselors to focus their attention on the conflicts and problems of such individuals that are hindering their interpersonal and academic development and performance.

Therapeutic interventions may focus on identifying inappropriate constructs and irrational beliefs that could be subject to change. At the same time, mentoring systems can be used where more experienced and sociable students can provide friendship and guidance 
to more reserved and unsociable competition avoiders. Hopefully, this would contribute to feelings of acceptance for these individuals and provide interpersonal support in what is essentially for them a hostile environment. In addition, counselors can encourage such individuals to join school clubs (e.g., service, acting, business,) that may require them to be more assertive and sociable. Such experiences could also broaden their views of the world and make them more open to experience. Also, it could be possible to assess changes in their attitudes and behaviors in a variety of life situations that are the result of therapeutic interventions aimed at the elimination of their fearful attitudes and behaviors underlying competition avoidance.

In athletics, coaches could focus as well on specific fears and anxieties that competition avoidance-prone individuals have in entering and being successful in competitive athletic activities. Competition avoiders tend to avoid all competitive situations, but these professionals could help these individuals see that not all competitive activities are to be avoided. Indeed, there are some competitive orientations that are psychologically healthy and interpersonally effective (e.g., personal development competition; Ryckman et al., 1996), whereas other competitive orientations are psychologically and interpersonally unhealthy (e.g., hypercompetitiveness; see Ryckman et al., 1990). In addition to distinguishing between such competitive orientation, attention and efforts then could be directed toward developing or adopting those values associated with competing in a healthy way (Ryckman et al., 1997).

As in the academic realm, coaches could also have mentoring programs for competition-avoidant recruits. Paired with older, more experienced athletes on the team, these individuals can be provided guidance, support and acceptance. Hopefully, such mentors could reinforce the "feeling" of being part of the team, that they will not be continually belittled or ridiculed by their teammates, but, instead, that they would receive support from them for putting out maximum effort and doing their best, no matter what their performance outcome (Ryckman et al., 2009). Mentors can also assure them that if they are belittled or ridiculed by hypercompetitive opponents, not to take it so seriously, but instead to look immediately to their own teammates for support and encouragement under such circumstances.

This research also suggests additional research to increase further our understanding of the goal-avoidant personality of the competition avoider. Specifically, future research may consider whether individuals higher in competition avoidance are less successful academically given their neurotic fears of being negatively evaluated by other students after they have competed in test situations. In addition to academic performance, research needs to consider whether competition avoiders are less successful in other domains as well (e.g., in sports, occupationally or professionally,). And, when having to engage in a competitive endeavor, research needs to consider whether competition avoiders are inclined to greater use of self-handicapping strategies. It also needs to be determined if people higher in competition avoidance are also less creative than individuals who are lower in competition avoidance because of their low openness to experience.

\section{CONCLUSION}

Horney (1973) had initially delineated two very different forms of neurotic competitiveness, hypercompetitiveness and competition avoidance. Hypercompetitiveness manifests in an indiscriminant need to compete and succeed at any cost as a neurotic means of maintaining and enhancing one's self-esteem. It is characterized by low self-esteem, narcissism, suspicion, hostility and aggressiveness toward others and a predisposition to be controlling, manipulative and exploitive of others and more (Burckle et al., 1999; Collier et al., 2010; Dru, 2003; Kaczor et al., 1991; Ross et al., 2003; Ryckman et al., 1990; 1997; 1994; 2002; Thornton et al., 2011).

In stark contrast, Horney considered those who recoil from or avoid competition to be similarly neurotic as well. Research on this aspect has only recently begun with the development of a psychometrically sound assessment with which to assess individual differences in competition avoidance (Ryckman et al., 2009). Nevertheless, initial research indicated that competition avoiders do indeed have higher levels of neuroticism (similar to their hypercompetitive counterparts), fear both success and failure due to what others may think of them (whether they succeed or fail) and are more likely to conform, agree with others and/or belittle themselves in order to secure and/or maintain the approval and acceptance of others (Ryckman et al., 2009).

Results of the present research further confirm the neurotic nature of those who recoil from competition as Horney had theorized some 75 years ago. Indeed, these individuals are more introverted, less outgoing and socialble and less open to experience, preferring instead to be conventional and not stand out, thereby not risking disapproval or rejection from others. Further research into the nature of those who recoil from 
competition is obviously indicated. As Horney originally postulated, they are likely to share many more of the same personality characteristics of those who are hypercompetitive.

\section{REFERENCES}

Burckle, M.A., R.M. Ryckman, J.A. Gold, B. Thornton and R.J. Audesse, 1999. Forms of competitive attitude and achievement orientation in relation to disordered eating. Sex Roles, 40: 853-870. DOI: 10.1023/A:1018873005147

Collier, S.A., R.M. Ryckman, B. Thornton and J.A. Gold, 2010. Competitive personality attitudes and forgiveness of others. J. Psychol., 144: 535-543. DOI: $10.1080 / 00223980.2010 .511305$

Costa, P.T. and R.R. McCrae, 1992. NEO PI-R Professional Manual. 1st Edn., PAR Psychological Assessment Resources, Inc., Odessa, FL., ISBN10: 9997924452.

Costa, P.T. and T.A. Widiger, 2002. Personality Disorders and the Five-Factor Model of Personality. 2nd Edn., American Psychological Association, Washington, DC., ISBN: 1557988269, pp: 493.

Dru, V., 2003. Relationships between an ego orientation scale and a hypercompetitive scale: their correlates with dogmatism and authoritarianism factors. Personality Individual Differences, 35: 1509-1524. DOI: 10.1016/S01918869(02)00366-5

Ehrhart, K.H., S.C. Roesch, M.G. Ehrhart and B. Kilian, 2008. A test of the factor structure equivalence of the 50-item IPIP five-factor model measure across gender and ethnic groups. J. Personality Assess., 90: 507-516. DOI: 10.1080/00223890802248869

Elliot, A.J. and K.M. Sheldon, 1997. Avoidance achievement motivation: A personal goals analysis. J. Personality Soc. Psychol., 73: 171-185. DOI: 10.1037/0022-3514.73.1.171

Eysenck, H.J. and S.B.G. Eysenck, 1994. Manual of the Eysenck Personality Questionnaire. 1st Edn., Educational Industrial Testing Service, San Diego, pp: 21.

Eysenck, H.J., 1991. Dimensions of personality: 16, 5 or 3?-Criteria for a taxonomic paradigm. Personality Individual Differences, 12: 773-790. DOI: 10.1016/0191-8869(91)90144-Z

Goldberg, L.R., 1990. An alternative "description of personality": The Big-Five factor structure. J. Personality Soc. Psychol., 59: 1216-1229. DOI: 10.1037/0022-3514.59.6.1216
Horney, K., 1973. Feminine Psychology. 1st Edn., Norton, New York, ISBN: 0393006867, pp: 269.

Kaczor, L.M., R.M. Ryckman, B. Thornton and R.H. Kuehnel, 1991. Observer hypercompetitiveness and victim precipitation of rape. J. Soc. Psychol., 131: 131-134. PMID: 1881128

McCrae, R.R. and P.T. Costa, 1987. Validation of the five-factor model of personality across instruments and observers. J. Personality Soc. Psychol., 52: 8190. DOI: 10.1037/0022-3514.52.1.81

Mervielde, I., 1999. Selected Papers from de Eighth European Conference on Personality held in Ghent, Belgium, July 1996. 1st Edn., Tilburg University Press, Tilburg, ISBN: 9789036199292, pp: 339.

Ross, S.R., M.K. Rausch and K.E. Canada, 2003. Competition and cooperation in the five-factor model: Individual differences in achievement orientation. J. Psychol.., 137: 323-337. DOI: 10.1080/00223980309600617

Ryckman, R.M., B. Thornton and J.A. Gold, 2009. Assessing competition avoidance as a basic personality dimension. Psychology, 143: 175-192. DOI: $10.3200 /$ JRLP.143.2.175-192

Ryckman, R.M., B. Thornton and J.C. Butler, 1994. Personality correlates of the hypercompetitive attitude scale: Validity tests of Horney's theory of neurosis. J. Personality Assessment, 62: 84-94. DOI: $10.1207 / \mathrm{s} 15327752$ jpa6201_8

Ryckman, R.M., B. Thornton, J.A. Gold and M.A. Burckle, 2002. Romantic relationships of hypercompetitive individuals. J. Soc. Clin. Psychol., 21: 517-530. DOI: 10.1521/jscp.21.5.517.22619

Ryckman, R.M., C.R. Libby, B.V.D. Borne, J.C. Butler and M.A. Lindner, 1997. Values of hypercompetitive and personal development competitive individuals. J. Personality Assess., 69: 271-283. DOI: 10.1207/s15327752jpa6902_2

Ryckman, R.M., M. Hammer, L.M. Kaczor and J.A. Gold, 1990. Construction of a hypercompetitive attitude scale. J. Personality Assess., 55: 630-639. DOI: $10.1080 / 00223891.1990 .9674097$

Ryckman, R.M., M. Hammer, L.M. Kaczor and J.A. Gold, 1996. Construction of a personal development competitive attitude scale. J. Personality Assess., 66: 374-385. DOI: 10.1207/s15327752jpa6602_15

Skaalvik, E.M., 1997. Self-enhancing and self-defeating ego orientation: Relations with task and avoidance orientation, achievement, self-perceptions, and anxiety. J. Educ. Psychol., 89: 71-81. DOI: 10.1037/0022-0663.89.1.71 
Thornton, B., R.M. Ryckman and J.A. Gold, 2011. Hypercompetitiveness and relationships: Further implications for romantic, family and peer relationships. Psychology, 2, 269-274. DOI: 10.4236/psych.2011.24043

Urdan, T. and M. Mestas, 2006. The goals behind performance goals. J. Educ. Psychol., 98: 354-365.

DOI: $10.1037 / 0022-0663.98 .2 .354$
Wiggins, J.S., 1996. The Five-Factor Model of Personality: Theoretical Perspectives. 1st Edn., Guilford Press, New York, ISBN: 157230068X, pp: 216. 